REVIEW

\title{
Acute endoscopic intervention in non-variceal upper gastrointestinal bleeding
}

\author{
R P Arasaradnam, M T Donnelly
}

Postgrad Med J 2005;81:92-98. doi: 10.1136/pgmi.2004.020867

Upper gastrointestinal bleeding is one of the commonest emergencies encountered by general physicians. Once haemodynamic stability has been achieved, therapeutic endoscopy is vital in control and arrest of bleeding. Various methods are available and the evidence is reviewed as to the most optimal approach. Clinical parameters including timing of endoscopy, risk stratification, and predictors of failure will also be discussed together with a summary of recommendations based on current available evidence.

Correspondence to: Dr R P Arasaradnam, Department of Gastroenterology Northern General Hospital, Sheffield Teaching Hospitals, Sheffield S5 7AU, UK ramesh.arasaradnam@ sth.nhs.uk

Submitted

19 February 2004

Accepted 1 June 2004 ts annual incidence is estimated at 50 to 150 per 100000 of the population while highest among the lowest socioeconomic groups. ${ }^{1}$ In 1957, the reported hospital mortality was $16 \%^{2}$ while in 1997 after a large audit of acute gastrointestinal bleeding in England, this was $11 \%{ }^{3}$ This striking lack in improvement in mortality may simply reflect an aging population with multiple comorbidity in whom upper gastrointestinal bleeding (UGIB) has been shown to have poorer outcome.

Table 1 lists the causes of UGIB, with peptic ulcer bleeding accounting for most cases. The control and arrest of bleeding is vital and in most cases this is achieved using therapeutic endoscopic intervention. Most (80\%) of bleeds (haemodynamically stable) do not re-bleed and thus do not require urgent endoscopic intervention. However, patients with actively bleeding peptic ulcer and non-bleeding visible vessel have $80 \%$ and $50 \%$ risk of re-bleeding respectively. ${ }^{1}$ It follows from these findings that endoscopic therapeutic haemostatic measures should be delivered in the first instance. Failure of such measures may require surgical intervention.

\section{CLINICAL ASSESMENT}

General management of patients presenting with acute UGIB requires immediate clinical evaluation, and resuscitation. This entails stabilisation of the systemic blood pressure and restoration of the intravascular volume. If there is any concern of airway compromise or if there is failure to respond after initial resuscitation, anaesthetic support should be sought early. Patients should be risk stratified according to low and high risk for rebleeding and mortality based on the Rockall score $^{3}$ (table 2). This comprises five categories (age, signs of shock, comorbidities, endoscopic findings, and description) and has been validated as predictors of rebleeding and mortality. ${ }^{4}$

\section{ENDOSCOPY: WHAT TO LOOK FOR ON THE REPORT}

Endoscopy in the hands of a skilled operator is the most sensitive and specific diagnostic procedure for determining cause and site of UGIB. ${ }^{5}$ Information from endoscopic examination should include (a) location (b) bleeding rate (oozing compared with spurting) (c) source of bleeding if multiple and (d) presence of stigmata of recent haemorrhage (SRH). SRH is more likely to be found if endoscopy is performed within 1218 hours of hospital admission. ${ }^{6}$ Certain endoscopic characteristics of SRH are important in predicting rebleeding (table 3 ). A clean ulcer base without SRH is a reliable indicator that the ulcer is not likely to rebleed. Such patients are deemed low risk and do not require prolonged hospital admission. ${ }^{7}$

\section{TIMING OF ENDOSCOPY}

Early endoscopy (within 24 hours), permits safe and prompt discharge of patients classified as low risk, while those at high risk would seem to have an improved outcome. ${ }^{7}$ Most centres in the UK are able to provide such a service while in some regions there is an on call bleed rota to provide a service out of hours.

\section{ENDOSCOPIC MANAGEMENT}

Needless to say, appropriate skill and training together with a competent assistant are prerequisites to achieve effective endoscopic haemostasis. Several techniques exist, which will be reviewed individually and in combination together with their relative merits and efficacy. Trials evaluating the different endoscopic modalities are varied in populations studied and trial design making direct comparisons difficult. Furthermore, some studies have small sample size and hence poor statistical power with regards to defined outcomes. In addition, as these techniques are technically demanding, there is danger in interpreting and extrapolating published trial data without taking into consideration the available local expertise. Clear defined outcome measures should include rates of rebleeding, surgery, and mortality, and to a lesser extent transfusion requirements or length of hospital stay. Table 4 shows categories of the available modalities.

Abbreviations: UGIB, upper gastrointestinal bleeding; $\mathrm{SRH}$, stigmata of recent haemorrhage; APC, argon plasma coagulation; BiPEC, bipolar electrocoagulation; $\mathrm{PPI}$, proton pump inhibitor 
Table 1 Causes of acute upper gastrointestinal haemorrhage'

\begin{tabular}{ll}
\hline Diagnosis & Approximate \% \\
\hline Peptic ulcer & $35-50$ \\
Gastroduodenal erosions & $8-15$ \\
Oesophagitis & $5-15$ \\
Varices & $5-10$ \\
Mallory Weiss tear & 15 \\
Upper gastrointestinal malignancy & 1 \\
Vascular malformation & 5 \\
Others & 5 \\
\hline
\end{tabular}

\section{INJECTION}

This method is simple, widely used, and the cheapest available haemostatic modality. Proposed mechanisms of action include tamponade, vasoconstriction, end arteritis, and possibly direct effect on clotting process at the site of arterial defect.

\section{Adrenaline (epinephrine)}

Chung et al in $1988^{8}$ reported $100 \%$ primary haemostasis in patients with active ulcer bleeding injected with 1:10 ?000 dilute adrenaline. Rebleeding still occurred (24\%) implying only a temporary vasoconstrictive effect but the need for surgery was subsequently reduced.

Sclerosants such as polidocanol, 5\% ethanolamine oleate, $3 \%$ sodium tetradecyl sulphate, and cyanoacrylate (tissue glue) have been used with varying results. To date no direct comparisons have been made with conservative treatment and only one (in abstract) with adrenaline. ${ }^{9}$ It stands to reason however, that the addition of a sclerosant agent, may achieve better rates of rebleeding. Table 5 shows some of the various combinations.

It is worthy of note that most of the above trials had small numbers and some were not powered to show mortality differences. Chung's controlled trial in 1996 comparing adrenaline and adrenaline with alcohol was the largest; $97.5 \%$ primary haemostasis was achieved with adrenaline alone while it was $94.9 \%$ with the combination-both impressive figures. In addition, hospital stay and time for ulcer healing was similar. The addition of alcohol does not confer any advantage.
Table 3 Endoscopic characteristics of stigmata of recent haemorrhage (SRH)'

\begin{tabular}{ll}
\hline Endoscopic features of SRH & Rebleeding (\%) \\
\hline Pulsatile arterial bleeding & 85 \\
Adherent clot & 40 \\
Pigmented protuberance & 20 \\
Flat blood spot on ulcer base & $5-10$ \\
\hline
\end{tabular}

\begin{tabular}{ll} 
Table 4 & Endoscopic management \\
\hline Modality & Type \\
\hline Injection & Adrenaline (epinephrine) \\
& Sclerosants \\
& Alcohol \\
& Thrombin \\
& Fibrin glue \\
Thermal & Heater probe \\
& Electrocoagulation \\
& Nd-Yag laser \\
& Argon plasma coagulation (APC) \\
Mechanical & Haemoclips \\
& Banding \\
& Staples \\
& Sutures \\
\hline
\end{tabular}

However, complications can occur with sclerosants as reported in animal studies ${ }^{14}$ and also in case reports. Experimental studies in dogs showed no advantage individually between adrenaline (1:10 000), ornipressin, $1 \%$ polidoconal, thrombin, or fibrin in heparin induced bleeding. However, the mucosal and submucosal injury (necrosis) was greatest in ethanol followed by polidoconal and thrombin sealants. Two case reports ${ }^{15}{ }^{16}$ have confirmed this and even reported a fatality. Adrenaline caused the least damage. Such severe reactions have not been reported with adrenaline or its effects on systemic circulation. Adrenaline injection seems to be safe.

Until recently, the ideal volume of injection had not been evaluated. Lin et $a^{17}$ have compared large (13-20 ml) with small $(5-10 \mathrm{ml})$ volume of injection of adrenaline. Primary haemostasis was achieved in all 156 patients randomised.

Table 2 Rockall score

\begin{tabular}{|c|c|c|c|c|}
\hline & Score 0 & Score 1 & Score 2 & Score 3 \\
\hline Age (y) & $<60$ & $60-79$ & 80 & \\
\hline Shock & $\begin{array}{l}\text { Pulse }<100 \\
\text { Systolic BP }>100\end{array}$ & $\begin{array}{l}\text { Pulse }>100 \\
\text { Systolic BP >100 }\end{array}$ & $\begin{array}{l}\text { Pulse }>100 \\
\text { Systolic }<100\end{array}$ & \\
\hline Comorbidity & Nil major & & $\begin{array}{l}\text { Heart failure } \\
\text { Ischaemic heart disease } \\
\text { Any other illnesses }\end{array}$ & $\begin{array}{l}\text { Renal failure } \\
\text { Liver failure } \\
\text { Disseminated cancer }\end{array}$ \\
\hline Endoscopic stigmata & $\begin{array}{l}\text { None } \\
\text { Dark spot }\end{array}$ & & $\begin{array}{l}\text { Blood in GIT } \\
\text { Adherent clot } \\
\text { Visible/spurting vessel }\end{array}$ & \\
\hline Diagnosis & $\begin{array}{l}\text { Mallory Weiss } \\
\text { No lesion seen }\end{array}$ & All other diagnosis & Upper Gl cancer & \\
\hline Pre-endoscopy score & Risk of death (\%) & Post-endoscopy score & Risk of death (\%) & Risk of rebleeding (\%) \\
\hline 7 & $75(45-100)$ & $8+$ & $40(30-51)$ & $37(27-47)$ \\
\hline 6 & $62(50-73)$ & 7 & $23(15-31)$ & $37(28-46)$ \\
\hline 5 & $35(27-43)$ & 6 & $12(6-17)$ & $27(20-34)$ \\
\hline 4 & $21(17-25)$ & 5 & $11(6-15)$ & 25 (19-31) \\
\hline 3 & $12(9-16)$ & 4 & $8(4-12)$ & $15(10-21)$ \\
\hline 2 & $6(3-9)$ & 3 & $2(0-4)$ & $12(7-17)$ \\
\hline 1 & $3(0.6-5)$ & $0-2$ & $0(0-1)$ & $6(3-8)$ \\
\hline 0 & $0(0-1.2)$ & & & \\
\hline
\end{tabular}




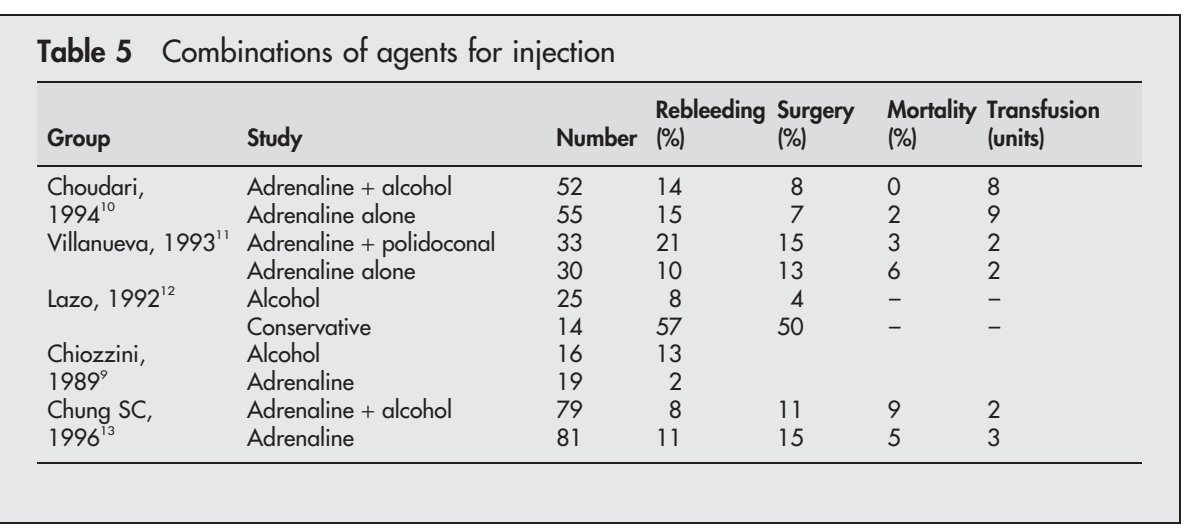

Rebleeding was lower by $15.4 \%$ in the large volume group compared with $30.8 \%$ in the small volume group. Numbers requiring surgery, transfusion requirements, or mortality were similar. Thus injecting large volumes $(>13 \mathrm{ml})$ can reduce the rate of rebleeding.

A primary role for tamponade in haemostasis with injection therapy has been suggested. The question as to whether tamponade alone was sufficient was addressed in a study by Laine et al. ${ }^{18}$ Patients were randomised to receive either saline solution (mean volume $30 \mathrm{ml}$ ) or bipolar electrocoagulation (BiPEC). Rebleeding was noted in $29 \%$ of saline group compared with $12 \%$ in the BiPEC group. In addition, number of units of blood transfused was higher ( 2 compared with 0 ) in the BiPEC group. Mortality was significantly different. From this one study, injection therapy seems to work by mechanisms other than tamponade alone.

In summary, endoscopic injection is of confirmed value but its mechanisms of action still remain unclear. For peptic ulcers, large volumes of adrenaline are required and combination with sclerosants confers no advantage.

\section{Fibrin glue and thrombin}

Table 6 shows studies comparing combinations of adrenaline and thrombin and adrenaline and fibrine with adrenaline alone.

The study by Kubba et $a l^{19}$ (table 6) compared a combination of adrenaline and thrombin with adrenaline alone. This study showed a statistical significance in reduction of rebleeding and mortality in the combination group but no difference was seen in surgery or transfusion requirements. Mortality as expected was high particularly those with already pre-existing comorbidities. Pescatore et a $2^{20}$ however compared a combination of fibrin (fibrin glue is a combination of fibrin and thrombin) with adrenaline compared with adrenaline alone. This study showed no difference between the two modalities. Comorbidities in this study were better stratified. More recently, Lin et $a^{21}$ have made a direct comparison between adrenaline and fibrin although with smaller numbers $(n=26$ each group). They showed rebleeding was higher in the adrenaline group (14 compared with 4) but transfusion requirements, surgery, and mortality were similar. However, numbers eventually treated were small.

Based on current evidence, there is no clear advantage of either fibrin or thrombin alone or in combination with adrenaline. No adverse effects have been reported with thrombin on systemic coagulation. In terms of cost, a $10 \mathrm{ml}$ $1: 10000$ vial of adrenaline is $£ 2.36$ inclusive of VAT while a $0.5 \mathrm{ml}$ vial fibrin glue (Histoacryl) costs $£ 7.49$ inclusive of VAT.

\section{THERMAL}

Thermal methods have the advantage of target irrigation, good coaptive coagulation, portability, and are comparatively economic once established but may incur initial capital cost. Several such methods are discussed below.

\section{Heater probe}

The heater probe transmits energy via a Teflon tipped catheter. Studies have shown it to be superior compared with conservative treatment in terms of reduction of rebleeding, surgery, and transfusion requirements. ${ }^{22}{ }^{23}$ Church et $a^{23}$ showed similar efficacy with bipolar electrocoagulation (BiCAP) with overall low complication rates. More recently, ${ }^{24}$ a randomised trial of 247 patients was performed comparing heater probe plus thrombin with heater probe alone. Ninety seven per cent primary haemostasis was achieved with no difference seen in rebleeding and emergency surgery. The authors concluded this combination conferred no addition advantage. Overall the heater probe is user friendly and while perforations can occur they are rare. The usual energy setting is $20 \mathrm{~W}$ but there has been no trial to date comparing the various energy settings.

\section{Electrocoagulation}

Haemostasis is achieved by heat and also through a tamponade effect. Monopolar coagulation has fallen into disrepute with early case series showing perforation and death. Alternatively, results with BiCAP have been more encouraging. BiCAP has eight separate electrodes over its surface. Electrical energy travels between the adjacent electrodes. Compared with placebo it is superior in terms of

\begin{tabular}{|c|c|c|c|c|}
\hline & \multicolumn{2}{|l|}{ Kubba et al 1996} & \multicolumn{2}{|c|}{ Pescatore ef al 2002} \\
\hline & Adrenline+thrombin & Adrenaline alone & Adrenaline+fibrin & Adrenaline alone \\
\hline Outcome & $n=70$ & $\mathrm{n}=70$ & $n=70$ & $n=65$ \\
\hline Transfusion number & 7 & $\begin{array}{l}14 \\
5\end{array}$ & 2 & 2 \\
\hline Emergency surgery & 3 & 5 & 4 & 6 \\
\hline Mortality & 0 & 7 & 2 & 2 \\
\hline
\end{tabular}


Table 7 Combination therapy trials

\begin{tabular}{|c|c|c|c|c|c|c|c|c|c|c|c|c|c|c|}
\hline & \multicolumn{3}{|c|}{ Chung S $1997^{37}$} & \multicolumn{5}{|c|}{ Lin HJ $1999^{38}$} & \multicolumn{4}{|c|}{ Gevers AM $2002^{39}$} & \multicolumn{2}{|c|}{ Chun HC $2003^{40}$} \\
\hline & $\mathrm{Adr}+\mathrm{HP}$ & $v$ & Adr & Adr & $v$ & BiPEC & $v$ & $A d r+B i p E C$ & Adr & $v$ & Clip & v Adr+Clip & $\mathrm{Adr}+\mathrm{HP}$ & $v \mathrm{Adr}+\mathrm{APC}$ \\
\hline Number & 136 & & 134 & 32 & & 32 & & 32 & 34 & & 35 & 32 & 97 & 88 \\
\hline $\begin{array}{l}\text { Primary } \\
\text { haemostasis }\end{array}$ & 135 & & 131 & 31 & & 30 & & 30 & 33 & & 30 & 29 & 93 & 86 \\
\hline Rebleed & 5 & & 12 & 11 & & 9 & & 2 & 5 & & 13 & 8 & 21 & 15 \\
\hline Transfusion & 3 & & 2 & 3 & & 2 & & 1 & 5 & & 4 & 4 & 2 & 2 \\
\hline Surgery & 8 & & 4 & 5 & & 2 & & 1 & & & & & 9 & 4 \\
\hline Mortality & 8 & & 7 & 3 & & 1 & & 1 & 0 & & 0 & 8 & 6 & 5 \\
\hline
\end{tabular}

reduced rebleeding, emergency surgery, and transfusion requirements. ${ }^{25} 26$ It seems to be at least comparable to heater probe. ${ }^{24}$ When compared with saline to evaluate the tamponade theory, Laine et al showed saline solution injection (mean volume $30 \mathrm{ml}$ ) was less effective compared with BiCAP. ${ }^{18}$

\section{Laser}

Nd-Yag laser compared with argon laser has been the most studied. Results have been conflicting with Swain et al ${ }^{27}$ showing reduction in rebleeding, emergency surgery, and even mortality in the laser treated group. Another group ${ }^{28}$ a year later who had a similar number of patients however showed a poorer outcome compared with controls. What was striking was that in the study by Swain et al, a single experienced endoscopist delivered all therapy. Thus for this therapeutic modality, outcome seems very much dependent on the skill of an endoscopist who is familiar with this technique. This has also been shown to be true in managing palliative gastrointestinal malignancy where there was good outcome when managed by a single endoscopist. ${ }^{29}$ On a practical level, this approach is technically difficult and expensive. Other equally and perhaps more efficient methods are readily available and thus this technique has gone out of favour.

\section{Argon plasma coagulation}

Argon plasma coagulation that is based on coagulation through a jet of argon gas alone is not sufficient in controlling spurting haemorrhage, and potentially dangerous for large non-bleeding vessels. This is because the thermal damage is superficial and hence more applicable to mucosal or superficial bleeding lesions such as gastric antral vascular ectasia. One trial ${ }^{30}$ has shown comparable efficacy with heater probe therapy in ulcer haemostasis (non-spurting). However, a later trial $^{31}$ in combination with adrenaline, achieved $98.1 \%$ primary haemostasis with $9.6 \%$ rebleed rate. Despite these two studies, most experts would not advocate its use in active or spurting bleeding for the reasons outlined above. $^{1}$

\section{MECHANICAL \\ Haemoclips}

Mechanical devices such as haemoclips have been used to aid in the control of primary haemostasis and rebleeding. Various comparisons have been made ${ }^{32}{ }^{33}$ but only Nishiaki et al, ${ }^{34}$ Lin HY et $a l^{35}$ and Chung et $a l^{36}$ have made direct comparisons. Chung et al have shown haemoclips, heater probe, and adrenaline to be of equal efficacy in primary haemostasis. Chung et al also showed less rebleeding in the group treated with haemoclips alone. Like laser therapy, this device is very much operator dependent. It can be technically challenging especially in patients with "difficult to approach" peptic ulcer bleeding. In this instance, injection therapy or thermal methods are more suitable. However, where there is active spurting applying at least two haemoclips at right angles is helpful to gain immediate arrest of bleeding. Several clips may need to be applied occasionally to gain complete haemostasis.

\section{COMBINATION THERAPY}

As the mechanisms for achieving primary haemostasis differ with injection and thermal methods, it is thus rational to investigate whether combining such modalities may offer an advantage.

Chung et $a l^{37}$ and later confirmed by Lin $e$ t $a l^{48}$ have shown in well designed trials that combining thermal methods with adrenaline injection reduced rebleeding rates compared with adrenaline injection alone. Data remain discordant regarding combination of injection therapy with haemoclip. Gevers et $a l^{39}$ found haemoclip inferior to adrenaline but Chung et al ${ }^{36}$ who studied 124 patients found that in the subgroup with spurting vessel, haemoclip alone or in combination with adrenaline injection, was better at achieving haemostasis. Thus at present, combination therapy using adrenaline injection combined with either a thermal or mechanical method seems most efficacious.

Table 7 list some of the various combination trials.

\section{MEDICAL TREATMENT}

A comprehensive review of pharmacotherapy in UGIB is beyond the scope of this review however, there is good evidence to support the use of continuous high dose intravenous proton pump inhibitor (PPI) infusion (omeprazole $80 \mathrm{mg}$ bolus followed by $8 \mathrm{mg} / \mathrm{h}$ ) for 72 hours. When used as an adjunct to endoscopic treatment, there was reduction in rates of rebleeding, blood transfusion requirements, and also hospital stay. Although there was a reduction in mortality seen this did not reach statistical significance. ${ }^{41}$ In addition, its role in those patients with adherent clots is somewhat controversial. The one large study that researched this issue showed minimal difference only and used intravenous boluses of $\mathrm{PPI}^{42}$ which is not sufficient to maintain $\mathrm{pH}$ above $6 .^{43}{ }^{44}$

\section{FAILURE OF ENDOSCOPIC THERAPY}

Precise timing for surgery is still much debated. With newer haemostatic modalities available and improving skills of the endoscopist, surgery is seen as a last resort when managing patients with UGIB. Not unreasonably, there is concern that persistence in repeated endoscopy will have adverse outcome on patients. Unfortunately, we cannot predict accurately who will fail to respond to endoscopic therapeutic intervention. Two studies however, have shown failure in treatment in patients with active bleeding, large ulcers, and those situated in the posterior duodenal wall. ${ }^{45}{ }^{46}$ More recently, Wong et a ${ }^{47}$ have shown that shocked patients requiring large volumes to resuscitate and haemoglobin $<1 \mathrm{~g} / \mathrm{l}$ at presentation are more likely to fail to achieve primary haemostasis endoscopically. 
Retreatment (second look) endoscopy of patients who failed primary therapeutic endoscopic measures, remains controversial. Lau et a ${ }^{48}$ have shown in 3473 patients where they achieved a remarkable $98.5 \%$ primary haemostasis, endoscopic retreatment rather than immediate surgery should be undertaken in patients who rebleed. Complications were higher in the surgery group with no differences in transfusion requirements or 30 day mortality. However, routine second look endoscopy is generally not recommended, ${ }^{49}$ except in those patients whose initial endoscopic examination was incomplete because of technical reasons (for example, excessive blood). Furthermore, the cost effectiveness of routine second look endoscopy has not been established..$^{50}$

More recently, another group ${ }^{51}$ have advocated early elective surgery for posterior duodenal wall bleeding ulcers, in high risk patients. However, only 22 patients were treated with only eight in the surgical arm after primary endoscopic treatment. Similarly, another study of 55 patients, ${ }^{52}$ showed an usually high rebleeding rate of $50 \%$ in the endoscopic retreatment arm but no difference in mortality compared with those who had early elective surgery. One explanation is that the endoscopic modality used was fibrin glue, which as shown above has a higher rebleeding rate compared with established injection therapy. The authors acknowledge this and thus the comparison is not ideal. Thus, it still remains impossible to accurately identify the subgroup of patients who will benefit from early surgical treatment after failed primary endoscopic haemostasis. ${ }^{46}{ }^{47}$ What is clear however, is that patients should be stratified individually based on their endoscopic findings, clinical status, and associated comorbidities. Early discussions with the surgeon should be undertaken as to appropriateness of early surgical intervention, if, at all. Some advocate the establishment of a dedicated gastrointestinal bleed unit, similar to a coronary care unit. Several such units have been reported in the UK with impressive results. ${ }^{53} 54$

\section{Box 1 Predictors of failure of endosocpic treatment}

- On going active bleeding

- Large ulcers $>1 \mathrm{~cm}$

- Site-posterior duodenal wall

- Shocked

- Large volume resuscitation (at presentation)

- $\mathrm{Hb}<1 \mathrm{~g} / \mathrm{l}$

\section{CONCLUSIONS}

Because of the differences in study design and populations treated, ranking of techniques from most to least effective is not possible. However, based on current literature combination therapy with adrenaline injection and thermal probes (preferably BiCAP) for actively bleeding peptic ulcers is the best option. For active spurting vessels, use of the haemoclip alone or in combination with adrenaline injection is recommended. For vascular mucosal lesions such as angiodysplasia, APC is safe and efficacious either alone or in combination with adrenaline injection. Finally, the endoscopist must always use the technique or modality with which they have the most experience and with which they are most confident of achieving primary haemostasis.
Box 2 Management of patients with UGIB - What to do:

- Resuscitate patient

- If airway insecure-involve anaesthetist early

- Rockall scoring before and after endoscopy

- Liaise with endoscopist (if out of hours service available contact endoscopist; if not liaise with general surgeon on-call)

- If endoscopy not possible urgently, consider starting intravenous omeprazole infusion (NB not evidence based)

\section{Endoscopist}

- Active bleeding peptic ulcer-combination of adrenaline injection and BiPEC

- Spurting vessel-haemoclip in combination with adrenaline injection

- Superficialvascular lesion-APC alone or in combination with adrenaline injection

Key references for further reading:

- British Society of Gastroenterology Endoscopy Committee. Non-variceal upper gastrointestinal haemorrhage: guidelines. Gut 2002;51:suppl iv.

- ASGE. Management of non-variceal acute upper gastrointestinal bleeding (UGIB). ASGE, 2002.

- Lau JYW, Sung JJY, Lam Y, et al et al. Endoscopic retreatment compared with surgery in patients with recurrent bleeding after initial endoscopic control of bleeding ulcers. N Engl J Med 1999;340: 751-6.

SELF ASSESSMENT QUESTIONS (TRUE (T)/FALSE (F); ANSWERS AT END OF REFERENCES)

1. Which of the statements relating to upper gastrointestinal bleeding (UGIB) is true?

(A) There has been significant improvement in mortality rates over the past half century.

(B) Oesophagitis is the commonest cause for UGIB

(C) Most cases do not rebleed after endoscopic therapeutic intervention

(D) Patients who have pulsatile arterial bleeding at endoscopy are at high risk of rebleeding.

(E) An anaesthetist should always be involved when endoscoping patients with UGIB

2. Which of these statements are correct?

(A) The thermal methods of endoscopic management achieve primary haemostasis by heat effect alone.

(B) Nd-Yag laser therapy is the most effective and widely available tool in the endoscopic management of UGIB

(C) APC is ideal for mucosal vascular malformations but not for control of spurting vessels.

(D) Fibrin is a combination of fibrinogen and thromboplastin

(E) Fibrin glue on its own is more effective when combined with adrenaline 
3. In the management of patients with UGIB

(A) Endoscopic therapy is by far the most important treatment even before the adequate resuscitation has taken place

(B) Elderly, shocked patients with a low haemoglobin have the best chance of achieving successful haemostasis with endoscopy alone.

(C) Surgical input should be sought early even if successful haemostasis has been achieved.

(D) The best combination of endoscopic therapy is with ethanol injection and laser

(E) Haemoclips are technically simple and inexpensive and hence should be attempted first as an endoscopic therapy regardless of site of ulcer.

4. In the management of patient with upper gastrointestinal bleeding

(A) Endoscopic therapy using thermal methods alone is ideal and most appropriate treatment

(B) If primary haemostasis fails, then it is not worth a second attempt as the chances of success at second attempt endoscopy are extremely low.

(C) The role and timing of surgery is clearly defined and usually superseded by endoscopy

(D) Mortality in the elderly population is much higher in those having surgery compared with those having a therapeutic endoscopy

(E) Primary haemostasis with combination therapy (injection + thermal) is achieved in most cases over $90 \%$ of the time.

\section{REFERENCES}

1 British Society of Gastroenterology Endoscopy Committee. Non-variceal upper gastrointestinal haemorrhage: guidelines. Gut 2002;51:suppl iv.

2 Avery Jones F. Haematemesis and melaena with special reference to bleeding peptic ulcer. BMJ 1957;ii:441-6.

3 Rockall TA, Logan RFA, Devlin HB, et al. Incidence of and mortality from acute upper gastrointestinal haemorrhage in the United Kingdom. BMJ 1995;311:222-6.

4 ASGE. Management of non-variceal acute upper gastrointestinal bleeding (UGIB). ASGE, 2002.

5 Fullarton GM, Birnie GG, MacDonald A, et al. Controlled trail of heater probe treatment in bleeding peptic ulcers. Br J Surg 1989;76:541-4

6 Barkun A, Bardou M, Marshall JK, et al. Consensus recommendations for managing patients with non-variceal upper gastrointestinal bleeding. Ann Intern Med 2003; 139:843-57

7 Sanders DS, Carter MJ, Goodchap RJ, et al. Prospective validation of the Rockall risk scoring system for upper GI haemorrhage in subgroups of patients with varices and peptic ulcers. Am J Gastroenterol 2002;97:630-5.

8 Messman H, Schaller P, Andus T, et al. Effect of programmed endoscopic follow-up examinations on the rebleeding rate of gastric or duodenal peptic ulcers treated by injection therapy; a prospective and randomised trial. Gastrointest Endosc 1994;40:34-9.

9 Chung SCS, Leung JWC, Steele RJC. Endoscopic injection of adrenaline for actively bleeding ulcers: a randomised trial. BMU 1988;296:1631-3.

10 Chiozzini G, Bortoluzzi F, Pallini P, et al. Controlled trail of absolute ethanol vs epinephrine as injection agent in gastroduodenal bleeding. Gastroenterology 1989;96:A86.

11 Choudari CP, Palmer KR. Endoscopic injection therapy for bleeding ulcer: a comparison of adrenaline alone and with adrenaline plus ethanolamine oleate. Gut 1994;35:608-10.

12 Villanueva C, Balanzo C, Espinos JC. Endoscopic injection therapy of bleeding ulcer: a prospective and randomised comparison of adrenaline alone or with polidoconal. J Clin Gastroenterol 1993;17:195-200.

13 Lazo MD, Andrale R, Medina MC, et al. Effect of injection sclerosis with alcohol on the rebleeding rate of gastroduodenal peptic ulcers with nonbleeding visible vessels: a prospective, controlled trial. Am J Gastroenterol 1992;87:843-6.

14 Chung SC, Leong HT, Chan AC, et al. Epinephrine or epinephrine plus alcohol for injection of bleeding ulcers: a prospective randomised trial. Gastrointest Endosc 1996;43:591-5.

15 Pundzius J, Jievaltas $M$. Experimental studies of injection agents for peptic ulcer bleeding endoscopic control. Int Surg 1998;83:280-2.
16 Levy J, Khakoo S, Barton R, et al. Fatal injection sclerotherapy of a bleeding peptic ulcer. (Letter). Lancet 1991;337:504.

17 Loperfido S, Patelli G, La Torre L. Extensive necrosis of gastric mucosa following injection therapy of a bleeding peptic ulcer. (Letter). Endoscopy 1990;22:785-6.

18 Lin HJ, hsieh YH, Tseng Gy, et al. A prospective randomised trial of large versus small volume endoscopic injection of epinephrine for peptic ulcer bleeding. Gastrointest Endosc 2002;55:615-19.

19 Laine L, Estrada R. Randomised trail of normal saline solution injection versus bipolar electrocoagulation for treatment of patients with high risk bleeding ulcers: Is local tamponade enough? Gastrointest Endosc 2002;55:6-10.

20 Kubba AK, Murphu W, Palmer KR. Endoscopic injection for bleeding peptic ulcer: a comparison of adrenaline with adrenaline plus human thrombin. Gastroenterology 1996;111:623-8.

21 Pescatore P, Jornod P, Borovicka, et al. Epinephrine versus epinephrine plus fibrin glue injection in peptic ulcer bleeding: a prospective randomised trial. Gastrointest Endosc 2002;55:348-53.

22 Lin HJ, Hsieh YH, Tseng GY, et al. Endoscopic injection with fibrin sealant versus epinephrine for arrest of peptic ulcer bleeding: a randomised, comparative trial. J Clin Gastroenterol 2002;35:218-21.

23 Jensen DM, Machicado GA, Kovacs TOG. Controlled randomised study of heater probe and BICAP for haemostasis of severe ulcer bleeding. Gastroenterology 1988;94:A208.

24 Church NI, Dallal HJ, Masson J, et al. A randomised trial comparing heater probe plus thrombin with heater probe plus placebo for bleeding peptic ulcer. Gastroenterology 2003;125:396-403.

25 Foster DN, Miloszewski K, Losowsky MS. Stigmata of recent haemorrhage in diagnosis and prognosis of upper gastrointestinal bleeding. BMJ 1978;1:1173-7.

26 O'Brien JD, Day SJ, Burnham WR. Controlled trial of small bipolar probes in the control of bleeding peptic ulcers. Lancet 1986;i:464-8.

27 Laine L. Multipolar electrocoagualtion for the treatment of ulcers with non bleeding visible vessels: A prospective, controlled trial. Gastroenterology 1988;94:A246.

28 Swain CP, Salmon PR, Kirkham JS. Controlled trail of Yd-Lag laser photocoagulation in bleeding peptic ulcers. Lancet 1986;i: $1113-17$.

29 Krejs GJ, Little KH, Westergaard H. Laser photocoagulation for the treatment of acute peptic ulcer bleeding. N Engl J Med 1987;316:1618-21.

30 Arasaradnam RP, Woodward T, Hancock P, et al. A 7 year experience of palliative laser therapy for upper and lower gastrointestinal malignancy in a district general hospital. Gut 2002;50(suppl 11):A106.

31 Cipolleta L, Bianco MA, Rotondano G, et al. Prospective comparison of argon plasma coagulator and heater probe in the endoscopic treatment of major peptic ulcer bleeding. Gastrointest Endosc 1998;48:191-5.

32 Scamporrino A, Occhigrossi G, lannetti A, et al. Endoscopic treatment combined with adrenaline injection and coagulation with argon plasma in gastroduodenal peptic ulcer bleeding. Ann ltal Chir plasma in gastrod $2001 ; 72: 707-13$

33 Lee YC, Wang HP, Yang Cs, et al. Endoscopic haemostasis of a bleeding marginal ulcer: haemoclipping or dual therapy with epinephrine injection and heater probe thermocoagulation. J Gastroenterol Hepatol 2002;17:1220-5.

34 Buffoli F, Graffeo M, Nicosia F, et al. Peptic ulcer bleeding: comparison of two haemostatic procedures. Am J Gastroenterol 2001;96:89-94.

35 Nishiaki $M$, Tada $M$, Yanai $H$, et al. Endoscopic haemostasis for bleeding peptic ulcer using a haemostatic clip or pure ethanol injection. Hepatogastroenterology 2000;47:1042-4.

36 Lin HJ, Hsieh YH Tseng GY, et al. A prospective randomised trial of endoscopic haemoclip versus heater probe thermocoagulation for peptic ulcer bleeding. Am J Gastroenterol 2002;87:2250-4.

37 Chung IK, Ham JS, Kim Hs, et al. Comparison of haemostatic efficacy of the endoscopic haemoclip method with hypertonic saline epinephrine injection and in combination of the two for the management of bleeding peptic ulcers. Gastrointest Endosc 1999;49:13-18.

38 Chung SCS, Lau YJ, Sung JJ, et al. Randomised comparison between adrenaline injection alone and adrenaline plus heater probe treatment for actively bleeding peptic ulcers. BMJ 1997;314:1307-11.

39 Lin $\mathrm{HJ}$, Tseng GY, Perng Cl, et al. Comparison of adrenaline injection and bipolar electrocoagulation for the arrest of peptic ulcer bleeding. Gut 1999:44:715-19.

40 Gevers AM, De Goede E, Simoens M, et al. A Randomised trial comparing injection therapy with haemoclip and with injection combined with haemoclip for bleeding ulcers. Gastrointest Endosc 2002;55:466-9.

41 Chun HC, Siu WT, Law BKB, et al. Randomised controlled trial comparing epinephrine injection plus heat probe coagulation versus epinephrine injection plus argon plasma coagulation for bleeding peptic ulcers. Gastrointest Endosc 2003;57:455-61

42 Lau YJ, Sung JJ, Lee KC, et al. Effect of iv omeprazole on recurrent bleeding after endoscopic treatment of bleeding peptic ulcers. N Engl J Med 2000;343:310-316

43 Jensen DM, Kovacs TOG, Jutabha R, et al. Randomised trial of medical or endoscopic therapy to prevent recurrent ulcer haemorrhage in patients with adherent clots. Gastroenterology 2002; 123:407-13.

$44 \mathrm{Li} \mathrm{Y,} \mathrm{Sha} \mathrm{W,} \mathrm{Nie} \mathrm{Y,} \mathrm{et} \mathrm{al.} \mathrm{Effect} \mathrm{of} \mathrm{intragastric} \mathrm{pH}$ on control of peptic ulcer bleeding. J Gastroenterol Hepatol 2000;15:148-54.

45 Arasaradnam RP, Riley SA. Optimal medical therapy with proton pump inhibitor (PPI) infusion to prevent recurrent ulcer haemorrhage in patients with adherent clots. Gastroenterology 2003;121:276

46 Villaneuva C, Balanzo J, Espinos JC. Prediction of therapeutic failure in patients with bleeding peptic ulcer treated with endoscopic injection. Dig Dis Sci 1993;38:2062-70. 
47 Choudari CP, Rajgopal C, Elton RA, et al. Failures of endoscopic therapy for bleeding ulcers: an analysis of factors. Am J Gastroenterol 1994;89:1968-72.

48 Wong SK, Yu LM, Lau JY, et al. Prediction of therapeutic failure after adrenaline injection plus heater probe treatment in patients with bleeding peptic ulcer. Gut 2002;50:322-5.

49 Lau JYW, Sung JJY, Lam Y, et al, et al. Endoscopic retreatment compared with surgery in patients with recurrent bleeding after initial endoscopic control of bleeding ulcers. N Engl J Med 1999;340:751-6.

50 Chung SC. Current Management of acute gastrointestinal bleeding Scand J Gastroenterol Suppl 2003;237:9-12.

51 Moni SP, Lubke T, Baldus SE, et al. Early elective surgery for bleeding ulcer in the posterior duodenal bulb. Own results and review of the literature. Hepatogastroenterology 2002;49:416-18.
52 Imhof M Ohmann C, Roher HD, et al. Endoscopic versus operative treatment in high-risk ulcer bleeding patients - results of a randomised study. Langenbecks Arch Surg 2003;387:327-36.

53 Sanders DS, Lobo AJ. Regional bleed unit-effect on upper gastrointestinal bleed outcome. Eur J Hepatogastroenterol (in press).

54 Masson J, Bramley PN, Herd K, et al. Upper gastrointestinal bleeding in an open-access dedicated unit. J R Coll Physicians Lond 1996;30:436-42.

\section{ANSWERS}

1. (A) F, (B) F, (C) T, (D) T, (E) F; 2. (A) F, (B) F, (C) T, (D)

F, (E) F; 3. (A) F, (B) F, (C) T, (D) F, (E) F; 4. (A) F, (B) F,

(C) F, (D) T, (E) T.

\section{FILLER}

\section{Drug companies' smartest and most flexible tool!}

M

y pen is from Pfizer and my post-it notes from Astra Zeneca and each time I use them I try to convince myself that they don't influence my prescribing decisions. Sadly I am only fooling myself. The messages from the drug companies must get through-otherwise they wouldn't use these tools. But of course the main tool that they are using is me.

The pens and post-it notes have got smaller and less useful over the years and drug companies may eventually get rid of them altogether. I wonder will they do the same to their smartest and most flexible tool-the doctor who takes their gifts. Roy Lilley writing for Pharmaceutical Marketing says that drug companies should "try linking treatment and drugs with therapy delivery and sell a new service. Put the people with the pill and learn about adding value to the medicine." (http://www.pmlive.com/pharm_market/opinion.cfm? showArticle $=1 \&$ ArticleID $=3074$ )

What could he mean by this? Does he mean bypassing the independent prescriber altogether and getting drug companies to run asthma clinics and allow their employees to prescribe inhalers? This idea may not be as outlandish as you think. Drug companies have long employed people to explain to patients how to take certain injections-expensive ones like interferon, that is. But increasingly we may see employees of drug companies prescribing medications too.

In the past they gave you the pen and the paper and the folder: are we just a small step away from them doing the prescribing for you as well? It could happen unless pretty soon someone shouts STOP.

K Walsh

BMJ Learning, BMJ Publishing Group, BMA House, Tavistock Square, London WCIH 9JR, UH; kmwalsh@bmigroup.com 